\title{
Postcolonic polypectomy pancreatitis
}

A 71-year-old man, who was following a colonoscopy surveillance program for previous colonic polyps, attended our endoscopy unit for routine colonoscopy. He had undergone his last endoscopic procedure in February 2007, during which a total of five polyps were resected (size range 7-15 mm). Histological examination revealed adenomatous polyps with lowgrade dysplasia.

The surveillance colonoscopy found three new polyps. One in the right colon $(10 \mathrm{~mm}$ in size), another in the proximal transverse colon $(8 \mathrm{~mm})$, and a third in the distal transverse colon (25 mm) ( $\bullet$ Fig. 1). The first two were resected using a cold forceps; for the third and largest polyp, however, we used a snare and endocut (ERBE ICC 200, Tübingen, Germany) following the injection of $5 \mathrm{~mL}$ of saline and $2 \mathrm{~mL}$ of adrenaline $1: 10000$ to facilitate resection and to prevent bleeding. Finally, it was necessary to use argon plasma coagulation (40 W, Q $1.8 \mathrm{~L} /$ minute) in order to eradicate some fragments that were technically difficult to resect $(\bullet$ Fig. 2 ).

The patient presented at the emergency room 12 hours after the procedure with epigastric pain and hyperamylasemia. Liver function tests showed a slight elevation of aminotransferases and bilirubin (less than twice the upper limit of normal). He was then diagnosed with pancreatitis, after other causes of hyperamylasemia had been excluded. Once admitted to our hospital, he underwent abdominal ultrasonography and computed tomography (CT), both of which did not demonstrate cholelithiasis, choledocholithiasis or any other potential cause of pancreatitis. Pancreatic inflammation seen with CT was limited to the pancreatic tail, which was in close relation to the distal transverse colon, where the largest polyp had been resected ( $\bullet$ Fig. 3 ).

Postpolypectomy pancreatitis due to the use of endocut was considered to be the most probable diagnosis. The patient had an uneventful recovery with conservative management, and was discharged from hospital a week later.

Endoscopy_UCTN_Code_CPL_1AJ_2AC

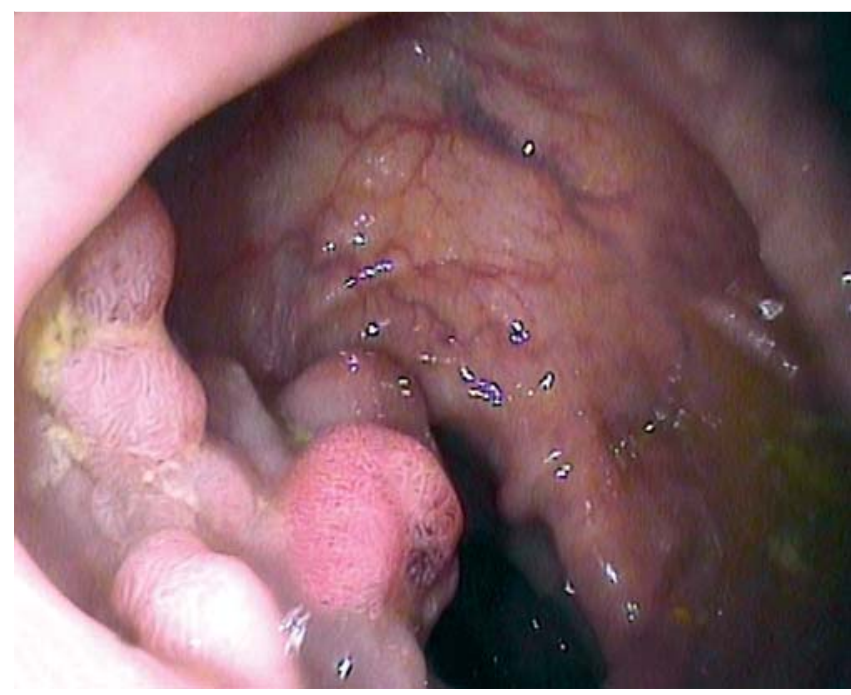

Fig. 1 Colonic polyp.

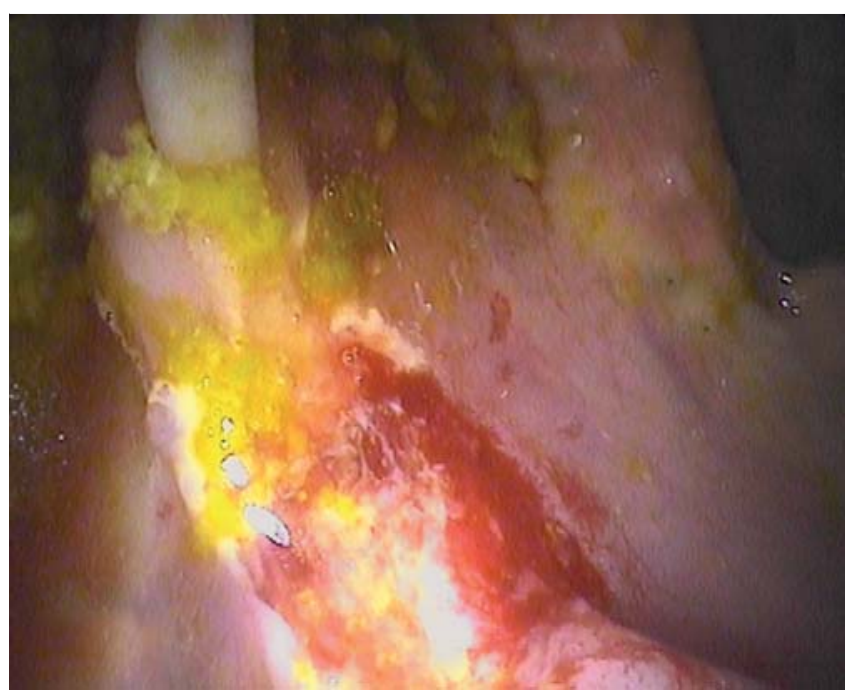

Fig. 2 Colonic polyp resection.

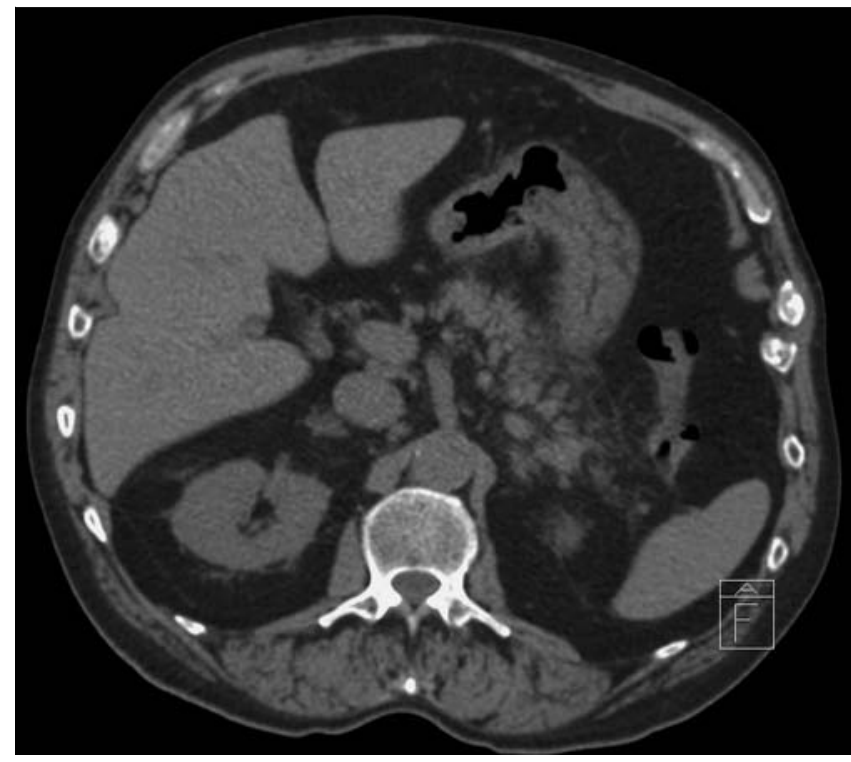

Fig. 3 Pancreatitis of the tail in close relation to the colon. 
J. I. Fortea, I. Marín Jimenez, O. Nogales Rincon, V. Flores Fernandez, T. Savescu, A. Madrid Vallenilla, P. Menchen Fernandez-Pacheco

Service of Digestive Diseases, Hospital

Gregorio Marañon, Madrid, Spain

\section{Bibliography}

DOI $10.1055 / \mathrm{s}-0029-1214967$

Endoscopy 2010; 42: E221 -E222

(c) Georg Thieme Verlag KG Stuttgart · New York . ISSN 0013-726X
Corresponding author

I. M. Jimenez, MD

Service of Digestive Diseases Hospital Gregorio Marañon

Dr Esquerdo 48

Madrid 28007

Spain

Fax: +34-1-914265024

drnachomarin@hotmail.com 